\section{PEER-REVIEWED ARTICLE}

Food Protection Trends, Vol 40, No. 6, p. 424-434 Copyright 2020 , International Association for Food Protection 2900 100th Street, Suite 309, Des Moines, IA 50322-3855
Kevin R. Roberts, ${ }^{* 1}$ Kevin Sauer,

Paola Paez ${ }^{1}$ and Michelle Alcorn²

${ }^{1}$ Center for Food Safety in Child Nutrition

Programs, Kansas State University,

148 Justin Hall, Manhattan, KS 66506, USA

'Dept. of Hospitality and Retail Management,

Texas Tech University, P.O. Box 41240,

Lubbock, TX 79409, USA

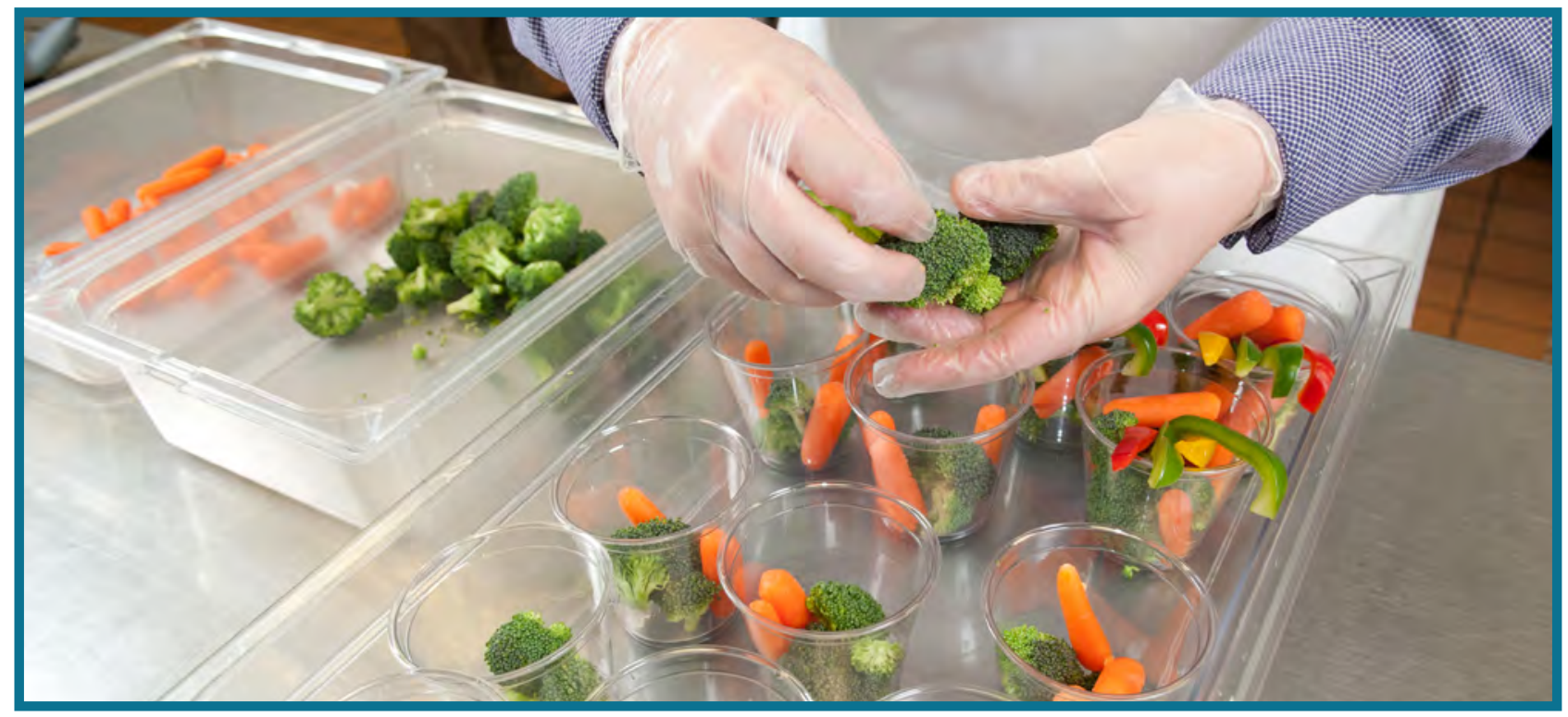

\title{
Use of the Theory of Planned Behavior to Determine Food Safety Behavioral Intentions among Child Nutrition Employees
}

\section{ABSTRAGT}

The purpose of this study was to use the theory of planned behavior to compare beliefs about three food safety practices between two groups of school nutrition employees: those who absolutely intended to practice each behavior versus those who did not. A questionnaire was used for data collection, and 3,850 surveys were mailed to 163 participating school districts. Data from 408 usable surveys were analyzed, for a response rate of $10.6 \%$. For each of the three behaviors, participants with less than absolute intentions were less likely to think that following proper practices in each of the three behaviors would decrease the chance that students would get sick, would ensure high food quality, and would keep students satisfied. For the three behaviors, people important to employees, such as the school nutrition director and supervisor, were identified by lower intenders as not being as supportive of their food safety efforts when compared with the beliefs among absolute intenders. In all instances, absolute intenders perceived stronger lack of control (i.e., a lower score) than did lower intenders. This study provides a theory-based investigation of how attitudes, subjective norms, and perceived behavioral controls affect food safety behaviors in the school nutrition environment.

\section{INTRODUCTION}

Through the National School Lunch Program, School Breakfast Program, and Summer Food Service Program, 7.5 billion meals and snacks are served annually across the United States (28). Originally, child nutrition programs were formed to combat child hunger, but today the programs also provide local agencies and communities with significant support and resources to deliver healthy meals to children (29). Considering the vast number of meals and snacks served through these programs, following recommended food safety behaviors could minimize the incidence of large-scale foodborne outbreaks, which would have serious implications for schools, school nutrition employees, and the children involved (29).

Foodborne illness continues to be a major public health concern in the United States. Foodborne pathogens account for more than 9.4 million cases of illness, 55,000 
hospitalizations, and 1,300 deaths each year in the United States (24). The Centers for Disease Control and Prevention (7) have identified five risk factors that contribute to foodborne illness attributed to food service operations. The U.S. Food and Drug Administration (30-33) has identified three of these five risks factors (personal hygiene, improper food holding time and temperature, and contaminated equipment or protection from contamination) as needing attention because low compliance for mitigation of these factors has been noted in food service establishments.

To promote food safety in schools, the Healthy HungerFree Kids Act of 2010 requires that school nutrition programs utilize food safety programs based on the Hazard Analysis Critical Control Points principles and be inspected at least twice per year (27). Food safety training is often the first line of defense to ensure proper practices among staff. School nutrition employees are among the most frequently trained employees across various food service sectors, given minimum professional standards and annual continuing education requirements. School nutrition employees are required to complete a minimum of $8 \mathrm{~h}$ of food safety and sanitation training yearly (27). However, previous research has revealed that increased employee knowledge of food safety through training may not be adequate for changing on-the-job behaviors (10, 11, 13, 19-22, 35).

Employees and managers have reported barriers, such as proper equipment and resources, training and education, and time pressures, that influence their ability to follow safe food practices $(11,22)$. Interventions to influence employees' behaviors should focus on the ability of these employees to properly perform the food safety behaviors (17). Thus, research is needed to identify the antecedents to behavior and behavioral intention when attempting to change behaviors.

The theory of planned behavior (TPB) has been used to study how behavioral intention best predicts actual behaviors $(15,16,18,34)$. The principle behind the TPB is that three antecedents directly influence a person's intention to perform a behavior: his or her attitudes, subjective norms, and perceived behavioral controls, which are referred to as direct measures (Fig. 1) (4). These antecedents can also be measured indirectly through salient beliefs, which are referred to as indirect measures. Salient beliefs refer to a person's behavioral, normative, and control beliefs that determine that person's attitude toward the behavior, subjective norm, and perceived behavioral control, respectively (3). Salient beliefs are the significant and fundamental beliefs a person holds about the behavior (2).

Behavioral beliefs include advantages and disadvantages of performing the behavior. When combined with the perception of a specific outcome, behavioral beliefs determine a person's attitude toward the behavior (4). Control beliefs include barriers to and facilitators of performing the behavior. When combined with the perception of power of these factors, control beliefs determine a person's perceived behavioral control. Normative beliefs are the perceived expectations of people who care about the performance of the behavior. When

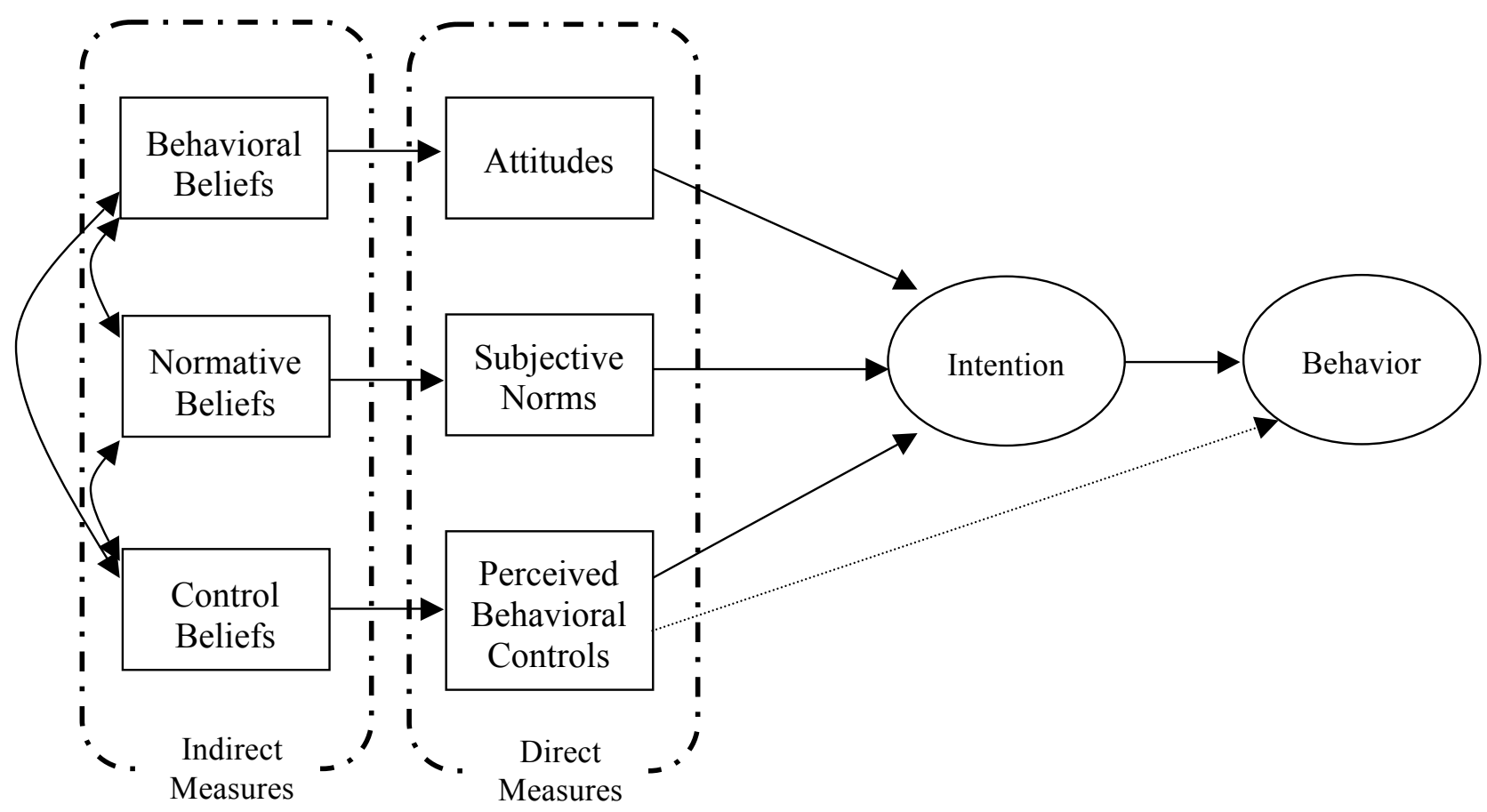

FIGURE 1. Theory of planned behavior (1). 
combined with a person's motivation to comply, normative beliefs determine that person's subjective norm (4). Therefore, the indirect measures of attitudes, subjective norms, and perceived behavioral controls include behavioral beliefs and outcome evaluations, normative beliefs and motivation to comply, and control beliefs and power of control, respectively.

After significant beliefs have been determined, interventions such as educational materials and training can be developed and/or modified specifically to elicit true behavior changes. For example, employees may feel that proper hand washing is not important because they had not washed their hands and, to their knowledge, no one became ill as a result. Interventions must target these specific beliefs by providing concrete examples, such as how foodborne outbreaks did occur because of poor performance of the behavior, to help employees understand why these beliefs are problematic.

This study was conducted to compare beliefs about three food safety practices - proper cleaning and sanitizing of food contact surfaces, proper hand washing, and use of a thermometer-between two groups of school nutrition employees: those who absolutely intended to practice each behavior and those who did not. The results provide information that food safety professionals can use to develop effective interventions that impact food safety training and behaviors in the child nutrition environment.

\section{MATERIALS AND METHODS}

\section{Instrument}

The TPB served as the theoretical basis for the study. A questionnaire was adapted from previous research and enhanced by the results of an elicitation study $(5,21)$, which followed the recommendations of Ajzen (3) by including both indirect measures (behavioral beliefs, normative beliefs, and control beliefs) and direct measures (attitudes, subjective norms, and perceptions of control) of behavioral intention among school nutrition employees. Ajzen noted that direct measures often have low reliability, but by utilizing indirect measures to evaluate the beliefs participants have about a particular concept, researchers can more fully understand each individual's attitudes, subjective norms, and perceived behavioral controls. The indirect measures are combined into a composite score, which represents the construct and reduces the concern about reliability (3).

The university Institutional Review Board approved the study protocol prior to data collection. For pilot testing, the survey was mailed to a convenience sample of 101 school nutrition employees. In addition to completing the questionnaire, participants provided feedback on clarity of the statements and time required to complete the questionnaire, and changes in format and content were incorporated according to recommendations. For example, the statement "Some of the questions may appear to be similar but they address different issues and practices" was added to the instructions section of the questionnaire to explain the repetitiveness of some of the statements. The data collected from the pilot test were not included in the final study.

The final questionnaire booklet included 31 questions to measure eight constructs, including direct and indirect measures for each behavior and respondent demographics. For each practice, the questions were the same, but the stem of the question changed based on the practice it was referring to (Appendix). Each practice had a total of eight questions. Before each section, a detailed definition of each behavior was provided. Employee attitudes were measured with a set of five semantic 7-point scales as recommended by Ajzen (4): goodbad, worthless-valuable, useless-useful, unpleasant-pleasant, and foolish-wise. Subjective norms, behavioral intentions, and perceived behavioral controls were measured with a 7-point scale anchored from strongly disagree (1) to strongly agree (7).

\section{Sample}

The sample comprised school nutrition employees affiliated with 163 school districts from seven randomly selected states. Each state represented one of the seven regions defined by the U.S. Department of Agriculture (USDA) Food and Nutrition Service (FNS) at the time of the study: Mid-Atlantic, Midwest, Mountain Plains, Northeast, Southeast, Southwest, and Western (Fig. 2). A list of school districts and operational demographics from the National Center for Education Statistics Web site (https://nces.ed.gov/ccd/districtsearch/) was compiled for each state and categorized by size to ensure representation of districts of different sizes. Districts were classified as mega for $\geq 40,000$ students, large for 20,000 to 39,999 students, medium for 2,500 to 19,999 students, and small for $<2,500$ students. A convenience sample of school districts was then selected, and the researchers attempted to distribute the questionnaires uniformly among the seven states based on availability of schools and district size. A total of 12 mega school districts, 30 large school districts, 54 medium school districts, and 67 small school districts were included in the study.

An electronic postcard was sent to school nutrition program directors to invite their employees to participate in the study and to alert them to expect questionnaires via mail delivery. The number of questionnaires sent to each school district was determined by the research team based on the size of the district. Each mega and large school district received 50 questionnaires, medium school districts received 20 questionnaires, and small school districts received 10 questionnaires. School nutrition directors or the school food authorities were asked to distribute all questionnaires to employees within their district.

A total of 3,850 surveys were mailed to selected school district directors, who were asked to distribute surveys to employees. The goal was to receive 500 complete and usable questionnaires for data analysis, which would represent a $14 \%$ response rate and would have been similar to previous research (12). Approximately 550 (15\%) surveys were mailed to each region. 


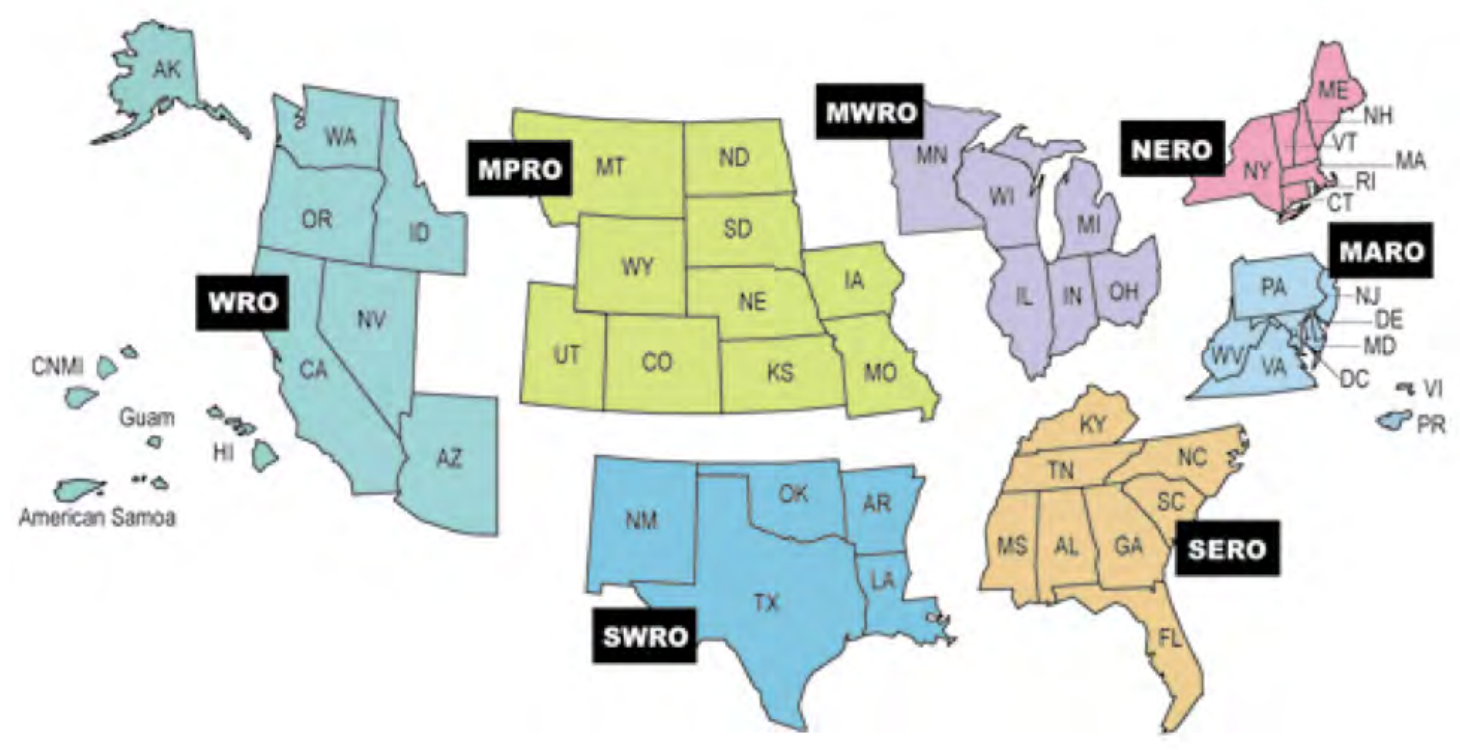

FIGURE 2. USDA FNS regional offices: MARO, Mid-Atlantic; MWRO, Midwest; MPRO, Mountain Plains; NERO, Northeast; SERO, Southeast; SWRO, Southwest; WRO, Western.

Each school district was provided with an introduction letter, questionnaires, and business reply envelopes to facilitate return of the questionnaires. The introduction letter, addressed to school nutrition directors, explained the purpose of the study and requested distribution of the questionnaire among employees. All school nutrition employees, except the director, were invited to participate. Following Dillman's (9) recommendation, a follow-up postcard was sent to prompt nonrespondents to complete the questionnaire. Postcards were sent by email to those with email addresses and by postal mail to those with no email address listed on the school district's website. A second reminder postcard was sent to those with email addresses 2 weeks after the first reminder.

\section{Data analysis}

Returned questionnaires were coded, and the data were processed and analyzed with the Statistical Package for Social Sciences (SPSS) version 18.0 (IBM, Armonk, NY). Descriptive statistics were analyzed for frequencies, means, and standard deviations. Cronbach's alpha was used to measure internal consistency with a threshold of 0.70 (8).

For the direct measures of attitude, perceived behavioral control, subjective norm, and behavioral intention, principal axis factor analysis with varimax rotation was conducted on the constructs independently. Using a minimum eigenvalue of 1.0, one factor was extracted for each of the three measures. Further analysis enabled comparison of absolute intenders (those who absolutely intended to perform the behavior) to other intenders that were not absolute. To assess differences between absolute intenders (behavioral belief score of 7.0 on a 7-point scale) and those who did not intend to perform the behavior, a series of $t$-tests were conducted for each behavior.

\section{RESULTS}

A total of 3,850 surveys were sent to participating school districts, and 580 surveys were returned. Of the 580 returned surveys, 172 were excluded because of patterned responses or missing data, resulting in 408 usable surveys, for a usable response rate of $10.6 \%$. According to Dillman (9), the number of completed responses obtained (408) still achieved a $95 \%$ confidence level with a $\pm 5 \%$ sampling error. The response rate is also comparable to that in previous research conducted by Sneed and Patten (26), Sauer et al. (23), and Grisamore and Roberts (12), who obtained response rates of 7, 9, and $14 \%$, respectively. The representability of the findings was improved given the standardization and homogeneity of practices and procedures found across schools, regardless of location or size. For example, school nutrition programs practices were homogenous because of national compliance with the standards published in the Child Nutrition and WIC Reauthorization legislation (27).

Of the 163 districts that were invited to participate, 43 districts were represented in the final sample. All states that were invited to participate were included in the final sample; thus, all USDA FNS regions were represented. Most of the returned surveys were from large (41\%) and medium (36\%) school districts and $18 \%$ were from small districts; no completed surveys were returned from the mega school districts. 
TABLE 1. Means and regression $\beta$ weights for theory of planned behavior direct measures for each of the food safety behaviors investigated

\begin{tabular}{l|c|c|c|c|c|c|c|c}
\hline & \multicolumn{2}{|c|}{ Attitude $^{a}$} & \multicolumn{2}{c|}{ Subjective norms ${ }^{b}$} & \multicolumn{2}{c|}{ Perceived control } & \multicolumn{2}{c}{ Intention } \\
\hline & Mean \pm SD & $\beta$ & Mean \pm SD & $\beta c$ & Mean \pm SD & $\beta$ & Mean \pm SD & Adjusted R $^{2}$ \\
\hline $\begin{array}{l}\text { Proper cleaning and } \\
\text { sanitizing of food contact } \\
\text { surfaces }\end{array}$ & $6.8 \pm 0.47$ & 0.076 & $6.8 \pm 0.40$ & $0.542^{*}$ & $6.4 \pm 1.07$ & $0.177^{*}$ & $6.9 \pm 0.31$ & 0.39 \\
\hline Proper hand washing & $6.9 \pm 0.40$ & 0.015 & $6.8 \pm 0.37$ & $0.564^{*}$ & $6.6 \pm 0.86$ & $0.153^{*}$ & $6.9 \pm 0.31$ & 0.40 \\
\hline Use of a thermometer & $6.9 \pm 0.37$ & -0.028 & $6.8 \pm 0.45$ & $0.615^{*}$ & $6.5 \pm 1.06$ & $0.152^{*}$ & $6.9 \pm 0.37$ & 0.44 \\
\hline
\end{tabular}

${ }^{a}$ Attitudes were measured using adjective pairs placed on opposite ends of a 7-point scale.

${ }^{b}$ Subjective norms, perceived control, and intention (respondent's intention to perform the behavior) were measured on a 7-point scale: 1 , strongly disagree; 7 , strongly agree.

${ }^{*} P \leq 0.001$.

Most respondents identified as female (91.4\%), 41 to 60 years of age $(57.8 \%)$, and with a high school diploma or some college education (79.7\%). Almost $15 \%$ of the respondents were $>60$ years old. More than $62 \%$ had been employed in the food service industry for 6 to 25 years; $>41 \%$ had been employed in their current position for $<5$ years. The majority (83.8\%) had food safety certification; ServSafe was the most prevalent type of certification (57.8\%).

\section{Direct TPB measures}

Cronbach's alpha was used to assess construct reliability among the direct measures, with 0.70 as the threshold to demonstrate consistency (8). All direct measures had reliability indices that were acceptable without removing any variable from the measures.

Independent multiple linear regressions were performed to evaluate the TPB model for each specific behavior. Each model utilized intention to perform the behavior as the dependent variable and attitude, subjective norm, and perceived behavioral control as the independent variables. Subjective norm and perceived behavioral control were the only consistent predictors for all three behaviors $(P \leq 0.001$; Table 1$)$.

\section{Absolute versus lower intenders}

Independent sample $t$-tests were conducted on the behavioral intention among those whose total belief score for the specific behavior was 7.0 on a 7-point scale versus those who had lower belief scores. Overall belief means were calculated multiplying the mean of the strength of each individual item (measured on a scale of 1 to 7 ) by the evaluation of that item (measured on a scale of -3 to 3 ). Possible scores range from -21 to 21 . Results are presented in Table 2.

\section{Behavioral beliefs}

In general, among the entire group of respondents, behavioral beliefs were high for all beliefs, with the exception of "takes too much time." However, all means were positive, indicating that in general the respondents were in favor of following proper food safety practices as described.

For each of the three behaviors, participants with less than absolute intentions to perform the behavior were less likely to think that following proper practices in each of the three behaviors would decrease the chance that students would get sick, ensure high food quality, and keep students satisfied (all $P \leq 0.05)$.

\section{Normative beliefs}

For normative beliefs, participants rated how likely each referent group or individual (immediate supervisor, school nutrition director, other employees, students, parents, teachers, school nurse, school administrators, and the health inspector) would think each behavior should be followed. As with behavioral beliefs, all normative belief means were generally high and positive. The positive response indicates that the respondents experience social pressure from each of the reference groups for following the proper practice for each behavior.

Results of comparisons between normative beliefs among absolute intenders and lower intenders (those with less than absolute intention to perform the behavior) across all three behaviors were similar to those for behavior beliefs. The health inspector, immediate supervisor, school nutrition director, school nurse, school administrators, teachers, other employees, parents, and students served by the program were all identified by lower intenders as not being as supportive of their food safety efforts when compared with the beliefs among absolute intenders $($ all $P \leq 0.05)$. 


\section{TABLE 2. Measures (t-tests) of belief for absolute versus lower intenders across all food}

safety practices ${ }^{a}$

\begin{tabular}{|c|c|c|c|c|c|c|}
\hline \multirow[t]{2}{*}{ Belief item $^{b}$} & \multicolumn{2}{|c|}{$\begin{array}{l}\text { Proper Cleaning and } \\
\text { Sanitizing of Food } \\
\text { Contact Surfaces }\end{array}$} & \multicolumn{2}{|c|}{ Proper Handwashing } & \multicolumn{2}{|c|}{$\begin{array}{c}\text { Using a Thermometer } \\
\text { to Check the Temperature } \\
\text { of Food }\end{array}$} \\
\hline & $\begin{array}{l}\text { Lower } \\
\text { Intender } \\
(n=60)\end{array}$ & $\begin{array}{l}\text { Absolute } \\
\text { Intender } \\
(n=348)\end{array}$ & $\begin{array}{l}\text { Lower } \\
\text { Intender } \\
(\mathbf{n}=\mathbf{5 7})\end{array}$ & $\begin{array}{l}\text { Absolute } \\
\text { Intender } \\
(\mathbf{n}=351)\end{array}$ & $\begin{array}{l}\text { Lower } \\
\text { Intender } \\
(\mathbf{n}=70)\end{array}$ & $\begin{array}{l}\text { Absolute } \\
\text { Intender } \\
(\mathbf{n}=337)\end{array}$ \\
\hline \multicolumn{7}{|l|}{ Behavioral beliefs } \\
\hline $\begin{array}{l}\text { Decrease the likelihood that } \\
\text { students will get sick }\end{array}$ & $18.88 \pm 3.54$ & $20.35 \pm 4.12^{*}$ & $18.88 \pm 3.70$ & $20.68 \pm 2.09^{*}$ & $18.67 \pm 4.55$ & $20.96 \pm 0.54^{*}$ \\
\hline Ensure high food quality & $15.28 \pm 6.21$ & $17.10 \pm 7.07^{*}$ & $15.81 \pm 5.64$ & $18.51 \pm 5.44^{*}$ & $17.19 \pm 5.49$ & $19.90 \pm 3.53^{*}$ \\
\hline Keep my students satisfied & $12.05 \pm 7.10$ & $14.49 \pm 7.91^{*}$ & $12.75 \pm 6.85$ & $16.59 \pm 6.69^{*}$ & $12.99 \pm 7.35$ & $17.12 \pm 6.57^{*}$ \\
\hline Take too much time & $1.56 \pm 4.48$ & $1.05 \pm 5.39$ & $2.05 \pm 7.57$ & $1.01 \pm 5.60$ & $1.19 \pm 6.46$ & $1.66 \pm 7.32$ \\
\hline \multicolumn{7}{|l|}{ Normative beliefs } \\
\hline Health inspector & $19.75 \pm 3.76$ & $20.87 \pm 1.07^{*}$ & $18.82 \pm 4.72$ & $20.90 \pm 0.96^{*}$ & $18.83 \pm 4.74$ & $20.84 \pm 1.19^{*}$ \\
\hline Immediate supervisor & $19.08 \pm 3.96$ & $20.51 \pm 2.49^{*}$ & $17.68 \pm 4.38$ & $20.72 \pm 1.57^{*}$ & $18.04 \pm 4.26$ & $20.79 \pm 1.37^{*}$ \\
\hline School nutrition director & $18.40 \pm 4.60$ & $20.25 \pm 3.30^{*}$ & $15.56 \pm 5.16$ & $20.44 \pm 2.89^{*}$ & $17.30 \pm 5.51$ & $20.52 \pm 2.65^{*}$ \\
\hline School nurse & $16.90 \pm 5.35$ & $19.35 \pm 4.46^{*}$ & $16.93 \pm 5.25$ & $20.13 \pm 3.15^{*}$ & $15.10 \pm 6.13$ & $19.41 \pm 4.39^{*}$ \\
\hline School administrators & $16.22 \pm 6.43$ & $18.86 \pm 5.00^{*}$ & $16.37 \pm 5.63$ & $19.76 \pm 3.72^{*}$ & $15.13 \pm 6.17$ & $19.08 \pm 4.84^{*}$ \\
\hline Teachers & $15.62 \pm 6.47$ & $18.33 \pm 5.40^{*}$ & $15.14 \pm 5.51$ & $19.38 \pm 4.06^{*}$ & $12.83 \pm 6.49$ & $17.74 \pm 6.31^{*}$ \\
\hline Other employees & $15.54 \pm 5.88$ & $18.18 \pm 5.34^{*}$ & $14.91 \pm 6.38$ & $19.60 \pm 3.88^{*}$ & $14.93 \pm 6.29$ & $19.61 \pm 3.65^{*}$ \\
\hline Parents & $14.98 \pm 5.90$ & $18.67 \pm 5.07^{*}$ & $14.14 \pm 5.56$ & $19.16 \pm 4.63^{*}$ & $12.39 \pm 6.22$ & $17.77 \pm 6.20^{*}$ \\
\hline My student & $11.34 \pm 7.45$ & $15.27 \pm 7.80^{*}$ & $12.68 \pm 6.77$ & $17.81 \pm 6.16^{*}$ & $10.68 \pm 7.19$ & $16.11 \pm 7.83^{*}$ \\
\hline \multicolumn{7}{|l|}{ Control beliefs } \\
\hline Time & $-1.45 \pm 8.03$ & $-3.91 \pm 8.58^{*}$ & $-2.39 \pm 8.41$ & $-6.32 \pm 13.20^{*}$ & $-3.06 \pm 7.99$ & $-6.18 \pm 6.97^{*}$ \\
\hline Lack of supplies & $-1.65 \pm 8.99$ & $-4.21 \pm 7.83^{*}$ & $-3.07 \pm 7.51$ & $-5.71 \pm 7.35^{*}$ & $-3.45 \pm 8.49$ & $-5.58 \pm 7.29^{*}$ \\
\hline Lack of equipment & $-1.97 \pm 7.86$ & $-4.24 \pm 7.54^{*}$ & $-2.91 \pm 7.34$ & $-5.58 \pm 6.98^{*}$ & $-3.20 \pm 7.91$ & $-5.23 \pm 6.83^{*}$ \\
\hline Funds & $-2.02 \pm 7.79$ & $-3.80 \pm 6.55$ & $-2.88 \pm 7.27$ & $-5.22 \pm 6.46^{*}$ & $-3.13 \pm 7.41$ & $-5.27 \pm 5.97^{*}$ \\
\hline Access to equipment & $-2.20 \pm 7.69$ & $-4.31 \pm 7.45^{*}$ & $-1.02 \pm 5.44$ & $-2.36 \pm 3.87^{*}$ & $-2.93 \pm 8.37$ & $-5.19 \pm 6.93^{*}$ \\
\hline
\end{tabular}

${ }^{a}$ Values are means \pm SD ( $t$-tests) and represent the strength of each individual item (scale of 1 to 7 ) multiplied by the evaluation of that item (scale of -3 to 3 ). Possible scores range from -21 to 21 . Asterisks indicate a significant difference between lower and absolute intenders $(P \leq 0.05)$.

${ }^{b}$ Behavioral beliefs: beliefs that a behavior will generate a certain consequence; these beliefs are linked to a person's attitude toward the behavior (3). Normative beliefs: beliefs that important individuals or groups have expectations for a person's behavior; these beliefs are linked to a person's subjective norms (3). Control beliefs: beliefs in the existence of barriers and facilitators that impact the performance of a behavior; these beliefs are linked to a person's perceived behavioral control.

\section{Control beliefs}

For control beliefs, respondents were asked how often not having the item affects their ability to perform each of the three food safety behaviors on the above scale. All control belief means for each of the three food safety practices were negative and just slightly lower than zero, meaning that all respondents felt they were not in control of following the recommended practice for each of the food safety behaviors. Results slightly below zero indicate that this feeling was not strong but still indicated a perceived lack of control.

Comparisons between absolute and lower intenders differed for the three behaviors related to control beliefs. Analysis of 
control beliefs related to proper cleaning and sanitizing of work surfaces revealed differences in all control beliefs $(P \leq 0.05)$, with the exception of funds. Differences were found between absolute and lower intenders on all control beliefs related to proper hand washing and use of a thermometer to check the temperature of food. In all instances, absolute intenders perceived stronger lack of control (i.e., a lower score) than did lower intenders $(P \leq 0.05)$, meaning absolute intenders perceived control barriers, such as lack of supplies and equipment, to performing the behaviors.

\section{DISCUSSION}

The TPB was applied in this study to determine ways in which food safety professionals can impact actual behaviors of employees in the child nutrition environment. However, the applications reach beyond child nutrition because food safety, training, and behavioral intention transcend practice settings and situations.

Research indicates that people will intend to perform a behavior when they perceive it as positive, when they believe that people important to them think they should perform that behavior, and when they perceive little to no control barriers. In this respondent sample, employees already held very positive attitudes about food safety practices, which could explain the fact that attitude was not a significant predictor of behavioral intention. Thus, intervention strategies that target attitude (i.e., why food safety practices should be followed, either negative or positive) would not likely influence behavioral intention in this group.

The strongest predictors of behavioral intent for these respondents were the social norms and perceived control beliefs. Intervention strategies that pay particular attention to social norms and perceptions of control are strongly correlated with behavioral intention, and increases in one or both of these constructs will result in an increase in the intention to perform the behavior.

Future training initiatives should also focus on those indirect beliefs where significant differences were found between absolute intenders and lower intenders. Increasing the beliefs of those with lower intentions to the level equal to or exceeding the beliefs of absolute intenders may increase the intention of employees to follow proper practices and thus improve actual behavior within the operation. For example, to increase behavioral beliefs across all three behaviors, a focus on the fact that following proper practices help to decrease the likelihood that students will get sick while keeping students satisfied and ensuring high food quality will lead to increased intentions among those who are not absolute intenders. Interventions should also emphasize the leadership exhibited by school nutrition directors, managers, and/or supervisors as role models. Individuals holding these positions are responsible for ensuring employees have the necessary resources, such as accessible and adequate facilities and equipment, for properly performing their food safety tasks.
Research has revealed that providing food safety training based on the theory of planned behavior can significantly improve food safety behaviors (14). To elicit measurable change in food safety behaviors among employees, we recommend the use of motivational strategies, such as emotional stories and personal examples, to supplement employee training and education. These strategies should focus on normative and control beliefs, which were the strongest predictors of behavior. Realistic and dramatic examples involving various stakeholders can help emphasize the importance of food safety and reducing risk, integrating the perspectives of those whom the school nutrition employee respects, including the school nutrition director, supervisor, or health inspector. These types of educational strategies should reinforce the positive normative beliefs that employees hold and help to dispel any falsely held control beliefs.

This study and resultant recommendations supplement previous research examining the theoretical components of employees' attitudes and can be used to inform the scientific community of issues germane to reducing food safety risks in the child nutrition sector. These findings advance our understanding of how best to implement proper food safety behaviors among employees in the school environment. The recommendations reflect previous research from the restaurant food service sector that underscored how employee knowledge affected appropriate food safety behavior (11, $21,22,35)$. However, knowledge is not the only element needed to improve employee behaviors and create noticeable behavioral changes. This study provides the first theory-based investigation of how attitudes, subjective norms, and perceived behavioral controls affect food safety behaviors in the school nutrition environment.

A limitation of this study is that actual behaviors were not observed, and the information collected was self-reported, which can involve selective memory, attribution, and exaggeration. Further research should explore direct observational methods that do not rely on self-reported data.

The intention to perform a behavior does not always translate into use of that behavior on the job. Sheeran and Web (25) noted that intentions translate into actual behavior only $50 \%$ of the time. However, intention has been noted as a better predictor of actual behavior than other behavioral theories $(6,19,35)$.

An additional limitation of this study is the method used to collect the data. More than $70 \%$ of the respondents were $\geq 40$ years of age. The written survey may have yielded a higher response among older employees, and an online data collection method might have yielded a higher response rate from younger respondents.

No completed surveys were obtained from mega districts. Future studies should consider additional recruitment methods, such as phone calls, to increase participation of mega school districts.

Although demographic information was collected from respondents, the role of each respondent in school operations 
was not included in the survey. Future studies should gather this information to be used in comparison with other demographic information, such as whether the respondent holds a food handling certification.

\section{ACKNOWLEDGMENT}

This project was funded in part with federal funds from the USDA. The contents of this report do not necessarily reflect the views or policies of the USDA nor does mention of trade names, commercial products, or organizations imply endorsement by the U.S. Government.

\section{REFERENCES}

1. Ajzen, I. 1991. The theory of planned behavior. Organ. Behav. Hum. Decis. Process 50:179-211.

2. Ajzen, I. 2000. Behavioral intentions based on the theory of planned behavior. Available at: http://people.umass.edu/aizen/pdf/tpb. intervention.pdf. Accessed 3 January 2020.

3. Ajzen, I. 2006. Constructing a TPB questionnaire: conceptual and methodological considerations. Available at: https://pdfs.semanticscholar.org/0574/b20bd58130dd5a961f1a2db10fd1fcbae95d.pdf. Accessed 3 January 2020

4. Ajzen, I. 2011. Behavioral interventions: design and evaluation guided by the theory of planned behavior, p. 74-100. In M. M. Mark, S. I. Donaldson, and B. C. Campbell (ed.), Social psychology for program and policy evaluation. Guilford, New York.

5. Alcorn, M., K. R. Roberts, K. L. Sauer, P. Paez, and T. Watkins. 2019. Assessing food safety behavior: salient beliefs of school nutrition employees. Food Prot. Trends 39:305-316

6. Armitage, C. J., and M. Conner. 2001. Efficacy of the theory of planned behaviour: a meta-analytic review. Br. J. Soc. Psychol. 40:471-499.

7. Centers for Disease Control and Prevention. 2016. Surveillance for foodborne disease outbreaks, United States, 2016 annual report Available at: https://www.cdc.gov/ fdoss/ pdf/2016_FoodBorneOutbreaks_508.pdf. Accessed $\overline{3}$ January 2020.

8. Cronbach, L. J. 1951. Coefficient alpha and the internal structure of tests. Psychometrika 16:297-334. Available at: https:// pdfs.semanticscholar.org/e985/ ac2e$151903000 \mathrm{cac} 310 \mathrm{ffbc5b} 2 \mathrm{cb} 4 \mathrm{fbb} 9 \mathrm{dd} 5 . \mathrm{pdf}$. Accessed 3 January 2020.

9. Dillman, D. A. 2007. Mail and internet surveys: the tailored design method, vol. 2 . Wiley, New York.

10. Giampaoli, J., J. Sneed, M. Cluskey, and H. F. Koenig. 2002. School foodservice directors' attitudes and perceived challenges to implementing food safety and HACCP programs. J. Child Nutr. Manag. 26. Available at: https:// schoolnutrition.org/ uploadedFiles $/ 5$ News and Publications/4 The Journal of_Child_Nutrition_and_Management/ Spring 2002/4-giampaoli1.pdf. Accessed 3 January 2020.
11. Green, L. R., and C. Selman. 2005. Factors impacting food workers' and managers' safe food preparation practices: a qualitative study. Food Policy 25:981-990.

12. Grisamore, A., and K. R. Roberts. 2014. Food recall attitudes and behaviors of school nutrition directors. J. Child Nutr. Manag. 38. Available at: http://schoolnutrition. org/ uploadedFiles/5_News and Publications/4_The Journal_of_Child_Nutrition and Management/Fall 2014/FoodRecallAttitudesBehaviorsSchoolNutritionDirectors. pdf. Accessed 3 January 2020.

13. Howells, A. D., K. R. Roberts, C. W. Shanklin, V. K. Pilling, L. A. Brannon, and B. B. Barrett. 2008. Restaurant employees' perceptions of barriers to three food safety practices. J. Am. Diet. Assoc. 108:1345-1349.

14. Husain, N., W. Wan Muda, N. Noor Jamil, N. Nik Hanafi, and R. Abdul Rahman. 2016. Effect of food safety training on food handlers' knowledge and practices. Br. Food J. 118:795-808.

15. Jenner, E. A., P. W. Watson, L. Miller, F Jones, and M. Scott. 2002. Explaining hand hygiene practice: an extended application of the theory of planned behavior. Psychol Health Med. 7:311-326.

16. Jimmieson, N. L., M. Peach, and K. M. White. 2008. Utilizing the theory of planned behavior to inform change management: an investigation of employee intentions to support organizational change. J. Appl. Behav. Sci. 44:237-262.

17. Mitchell, R. E., A. M. Fraser, and L. B. Bearon. 2007. Preventing foodborne illness in food service establishments: broadening the framework for intervention and research on safe food handling behaviors. Int. J. Environ. Health Res. 17:9-24.

18. O’Boyle, C. A., S. J. Henly, and E. Larson. 2001. Understanding adherence to hand hygiene recommendations: the theory of planned behavior. Am. J. Infect. Control 29:352-360.

19. Park, S., T. Kwak, and H. Chang. 2010 Evaluation of the food safety training for food handlers in restaurant operations. Nutr. Res. Pract. 4:58-68.

20. Pilling, V. K., L. A. Brannon, C. W. Shanklin, A. D. Howells, and K. R. Roberts. 2008. Identifying specific beliefs to target to improve restaurant employees' intentions for performing three important food safety behaviors. J. Am. Diet. Assoc. 108:991-997.
21. Roberts, K. R., and B. B. Barrett. 2011. Restaurant managers' beliefs about food safety training: an application of the theory of planned behavior. J. Foodserv. Bus. Res. 14:206-225.

22. Roberts, K. R., B. B. Barrett, A. D. Howell, C. W. Shanklin, V. K. Pilling, and L. A. Brannon. 2008. Food safety training and foodservice employees' knowledge and behavior. Food Prot. Trends 28:252-260.

23. Sauer, K., E. Patten, K. R. Roberts, and M. Schartz. 2018. Management of food allergies in schools. J. Child Nutr. Manag. 42. Available at: https://schoolnutrition. org/uploadedFiles/5_News_and_Publications/4 The Journal of Child Nutrition and_Management/Fall_2018/Fall2018Management-of-Food-Allergies-in-Schools. pdf. Accessed 3 January 2020.

24. Scallan, E., R. M. Hoekstra, F. J. Angulo, R. V. Tauxe, M.-A. Widdowson, S. L. Roy, J. L. Jones, and P. M. Griffin. 2011. Foodborne illness acquired in the United States-major pathogens. Emerg. Infect. Dis. 17: 7-15.

25. Sheeran, P., and T. L. Webb. 2016. The intention-behavior gap. Soc. Pers. Psychol. Compass 10:503-518.

26. Sneed, J., and E. V. Patten. 2014. Current practices for school field trip meals: summary report. Center of Excellence for Food Safety Research in Child Nutrition Programs, Kansas State University, Manhattan.

27. U.S. Congress. 2010. Healthy, Hunger-Free Kids Act of 2010, 42 U.S.C. \$3307. Available at: https://www.congress.gov/bill/111th-congress/senate-bill/ 3307?q=\%7B\%22 search $\% 22 \% 3 \mathrm{~A} \% 5 \mathrm{~B} \% 22$ healthy+hunger\%22\%5D\%7D\&r=1. Accessed 3 January 2020.

28. U.S. Department of Agriculture, Food and Nutrition Service. 2019. National school lunch program: total participation, FY 2015-2019. Available at: https://fns-prod. azureedge.net/sites/default/files/resource-files/01slfypart-12.19.pdf. Accessed 3 January 2020.

29. U.S. Department of Agriculture, Food and Nutrition Service. 2019. School meals: child nutrition programs. Available at: https:// www.fns.usda.gov/school-meals/child-nutrition-programs. Accessed 20 December 2019. 
30. U.S. Food and Drug Administration. 2004. FDA report on the occurrence of foodborne illness risk factors in selected institutional foodservice, restaurant, and retail food store facility types. Available at: https://wayback.archive-it org/7993/20170406023011/ https://www. fda.gov/downloads/Food/GuidanceRegulation/RetailFoodProtection/FoodborneIllnessRiskFactorReduction/UCM423850.pdf. Accessed 20 December 2019.

31. U.S. Food and Drug Administration. 2009. FDA report on the occurrence of foodborne illness risk factors in selected institutional foodservice, restaurant, and retail food store facility types. Available at: https://wayback. archive-it.org/7993/20170406023004/ https://www.fda.gov/Food/GuidanceRegulation/RetailFoodProtection/FoodborneIllness RiskFactorReduction/ucm224321.htm. Accessed 20 December 2019.
32. U.S. Food and Drug Administration. 2010. FDA trend analysis report on the occurrence of foodborne illness risk factors in selected institutional foodservice, restaurant, and retail food store facility types (1998-2008). Available at: https://wayback.archive-it. org/7993/20170406022950/https://www. fda.gov/Food/GuidanceRegulation/RetailFoodProtection/FoodborneIllnessRiskFactorReduction/ucm223293.htm. Accessed 20 December 2019.

33. U.S. Food and Drug Administration. 2018. FDA report on the occurrence of foodborne illness risk factors in fast food and full-service restaurants, 2013-2014. Available at: https:// www.fda.gov/downloads/Food/GuidanceRegulation/RetailFoodProtection/FoodborneIllnessRiskFactorReduction/UCM625005.pdf. Accessed 20 December 2019.
34. Webb, T. L., and P. Sheeran. 2006. Does changing behavioral intentions engender behavior change? A meta-analysis of the experimental evidence. Psychol. Bull. 132:249-268.

35. Yu, H., J. Neal, M. Dawson, and J. Madera. 2018. Implementation of behavior-based training can improve food service employees' handwashing frequencies, duration, and effectiveness. Cornell Hosp. Q. 59:70-77.

APPENDIX. Sample of questions used for the survey School Foodservice Employees' Attitudes and Knowledge of Performing Behaviors Related to Food Safety

In this questionnaire you will be asked to respond to questions about your attitudes and knowledge of performing behaviors related to three food safety practices: proper cleaning and sanitizing of food contact surfaces, proper hand washing, and using a thermometer to check the temperature of food. Please read each question carefully. Some of the questions may appear to be similar but they address different issues and practices.

The first food safety task we are going to discuss is PROPER CLEANING AND SANITIZING OF FOOD CONTACT SURFACES BY:

-Not allowing raw food to come into contact with ready-to-eat foods.

- Cleaning and/or sanitizing all food contact surfaces (hands, countertops, cutting surfaces, equipment, dishes, and utensils) between each use.

-Cleaning and sanitizing all food contact surfaces when switching from one food preparation task to another.

1. Proper cleaning and sanitizing of food contact surfaces will

\begin{tabular}{l|c|c|c|c|c|c|c}
\hline Statement & $\begin{array}{c}\text { Strongly } \\
\text { disagree }\end{array}$ & Disagree & Slightly disagree & Neutral & $\begin{array}{c}\text { Slightly } \\
\text { agree }\end{array}$ & $\begin{array}{c}\text { Agree } \\
\text { agree }\end{array}$ \\
\hline Keep my students satisfied & 1 & 2 & 3 & 4 & 5 & 6 & 7 \\
\hline $\begin{array}{l}\text { Decrease the likelihood that } \\
\text { students will get sick }\end{array}$ & 1 & 2 & 3 & 4 & 5 & 6 & 7 \\
\hline Ensure high food quality & 1 & 2 & 3 & 4 & 5 & 6 & 7 \\
\hline Take too much time & 1 & 2 & 3 & 4 & 5 & 6 & 7 \\
\hline
\end{tabular}

2. How important is each of the following items to you for using proper cleaning and sanitizing of food contact surfaces?

\begin{tabular}{l|c|c|c|c|c|c}
\hline Statement & $\begin{array}{c}\text { Extremely } \\
\text { unimportant }\end{array}$ & Unimportant & $\begin{array}{c}\text { Slightly } \\
\text { unimportant }\end{array}$ & $\begin{array}{c}\text { Seutral } \\
\text { important }\end{array}$ & $\begin{array}{c}\text { Extremely } \\
\text { Important }\end{array}$ \\
\hline Keeping my students satisfied & 1 & 2 & 3 & 4 & 5 \\
\hline $\begin{array}{l}\text { Decreasing the likelihood that } \\
\text { students will get sick }\end{array}$ & 1 & 2 & 3 & 5 \\
\hline Ensuring high food quality & 1 & 1 & 2 & 3 & 4 & 5 \\
\hline Taking extra time & & 5 & 4 & 5 \\
\hline
\end{tabular}


3. think(s) that I should use proper cleaning and sanitizing of food contact surfaces.

\begin{tabular}{l|c|c|c|c|c|c|c}
\hline Statement & $\begin{array}{c}\text { Strongly } \\
\text { disagree }\end{array}$ & Disagree & Slightly disagree & Neutral & $\begin{array}{c}\text { Slightly } \\
\text { agree }\end{array}$ & $\begin{array}{c}\text { Agree } \\
\text { agree }\end{array}$ \\
\hline My immediate supervisor & 1 & 2 & 3 & 4 & 5 & 6 & 7 \\
\hline The school nutrition director & 1 & 2 & 3 & 4 & 5 & 6 & 7 \\
\hline Other employees & 1 & 2 & 3 & 4 & 5 & 6 & 7 \\
\hline My students & 1 & 2 & 3 & 4 & 5 & 6 & 7 \\
\hline Parents & 1 & 2 & 3 & 4 & 5 & 6 & 7 \\
\hline Teachers & 1 & 2 & 3 & 4 & 5 & 6 & 7 \\
\hline The school nurse & 1 & 2 & 3 & 4 & 5 & 6 & 7 \\
\hline School administrators & 1 & 2 & 3 & 4 & 5 & 6 & 7 \\
\hline The health inspector & 2 & 3 & 4 & 5 & 6 & 7 \\
\hline
\end{tabular}

4. Generally speaking, how much do you care what and sanitizing food contact surfaces?

think(s) you should do in regards to properly cleaning

\begin{tabular}{l|c|c|c|c|c|c|c}
\hline Statement & Not at all & Barely & A little & Neutral & Somewhat & Much & Very much \\
\hline Your immediate supervisor & 1 & 2 & 3 & 4 & 5 & 6 & 7 \\
\hline The school nutrition director & 1 & 2 & 3 & 4 & 5 & 6 & 7 \\
\hline Other employees & 1 & 2 & 3 & 4 & 5 & 6 & 7 \\
\hline My students & 1 & 2 & 3 & 4 & 5 & 6 & 7 \\
\hline Parents & 1 & 2 & 3 & 4 & 5 & 6 & 7 \\
\hline Teachers & 1 & 2 & 3 & 4 & 5 & 6 & 7 \\
\hline The school nurse & 1 & 2 & 3 & 4 & 5 & 6 & 7 \\
\hline School administrators & 1 & 2 & 3 & 4 & 5 & 6 & 7 \\
\hline The health inspector & 1 & 2 & 3 & 4 & 5 & 6 & 7 \\
\hline
\end{tabular}

5.

makes it more difficult for me to properly clean and sanitize food contact surfaces:

\begin{tabular}{l|c|c|c|c|c|c|c}
\hline Statement & $\begin{array}{c}\text { Strongly } \\
\text { disagree }\end{array}$ & Disagree & Slightly disagree & Neutral & $\begin{array}{c}\text { Slightly } \\
\text { agree }\end{array}$ & $\begin{array}{c}\text { Strongly } \\
\text { agree }\end{array}$ \\
\hline Limited time & 1 & 2 & 3 & 4 & 5 & 6 & 7 \\
\hline Limited funds & 1 & 2 & 3 & 4 & 5 & 6 & 7 \\
\hline Lack of proper equipment & 1 & 2 & 3 & 4 & 5 & 6 & 7 \\
\hline Lack ofaccess toproperequipment & 1 & 2 & 3 & 4 & 5 & 6 & 7 \\
\hline Lack of available supplies & 1 & 2 & 3 & 4 & 5 & 6 & 7 \\
\hline
\end{tabular}

6. How often does

affect you from properly cleaning and sanitizing food contact surfaces?

\begin{tabular}{l|c|c|c|c|c|c|c}
\hline Statement & Very rarely & Rarely & Slightly rarely & Neutral & $\begin{array}{c}\text { Slightly } \\
\text { frequently }\end{array}$ & $\begin{array}{c}\text { Frequently } \\
\text { frequently }\end{array}$ \\
\hline Limited time & 1 & 2 & 3 & 4 & 5 & 6 & 7 \\
\hline Limited funds & 1 & 2 & 3 & 4 & 5 & 6 & 7 \\
\hline Lack of proper equipment & 1 & 2 & 3 & 4 & 5 & 6 & 7 \\
\hline $\begin{array}{l}\text { Lack of access to proper } \\
\text { equipment }\end{array}$ & 1 & 2 & 3 & 4 & 5 & 6 & 7 \\
\hline Lack of available supplies & 1 & 2 & 3 & 4 & 5 & 6 & 7 \\
\hline
\end{tabular}


7. Each pair of (A) and (B) words are opposites. Please complete the following statement with the appropriate item: "For me to properly clean and sanitize food contact surfaces is ".

\begin{tabular}{l|lllllll|l}
\hline (A) Extremely bad & 1 & 2 & 3 & 4 & 5 & 6 & 7 & (B) Extremely good \\
\hline (A) Extremely worthless & 1 & 2 & 3 & 4 & 5 & 6 & 7 & (B) Extremely valuable \\
\hline (A) Extremely useless & 1 & 2 & 3 & 4 & 5 & 6 & 7 & (B) Extremely useful \\
\hline (A) Extremely unpleasant & 1 & 2 & 3 & 4 & 5 & 6 & 7 & (B) Extremely pleasant \\
\hline (A) Extremely foolish & 1 & 2 & 3 & 4 & 5 & 6 & 7 & (B) Extremely wise \\
\hline
\end{tabular}

8. Please respond to the following questions and chose the most appropriate answer.

\begin{tabular}{|c|c|c|c|c|c|c|c|}
\hline Statement & $\begin{array}{l}\text { Strongly } \\
\text { disagree }\end{array}$ & Disagree & Slightly disagree & Neutral & $\begin{array}{l}\text { Slightly } \\
\text { agree }\end{array}$ & Agree & $\begin{array}{l}\text { Strongly } \\
\text { agree }\end{array}$ \\
\hline $\begin{array}{l}\text { Most people who are } \\
\text { important to me think that } \\
\text { I should properly clean and } \\
\text { sanitize food contact surfaces }\end{array}$ & 1 & 2 & 3 & 4 & 5 & 6 & 7 \\
\hline $\begin{array}{l}\text { I plan to properly clean and } \\
\text { sanitize food contact surfaces }\end{array}$ & 1 & 2 & 3 & 4 & 5 & 6 & 7 \\
\hline $\begin{array}{l}\text { It is expected that I will } \\
\text { properly clean and sanitize } \\
\text { food contact surfaces }\end{array}$ & 1 & 2 & 3 & 4 & 5 & 6 & 7 \\
\hline $\begin{array}{l}\text { The people in my life whose } \\
\text { opinions I value would want } \\
\text { me to properly clean and } \\
\text { sanitize food contact surfaces }\end{array}$ & 1 & 2 & 3 & 4 & 5 & 6 & 7 \\
\hline $\begin{array}{l}\text { It is mostly up to me whether } \\
\text { I properly clean and sanitize } \\
\text { food contact surfaces }\end{array}$ & 1 & 2 & 3 & 4 & 5 & 6 & 7 \\
\hline $\begin{array}{l}\text { I will try to properly clean and } \\
\text { sanitize food contact surfaces }\end{array}$ & 1 & 2 & 3 & 4 & 5 & 6 & 7 \\
\hline $\begin{array}{l}\text { I have complete control over } \\
\text { the use of proper cleaning } \\
\text { and sanitizing of food contact } \\
\text { surfaces }\end{array}$ & 1 & 2 & 3 & 4 & 5 & 6 & 7 \\
\hline $\begin{array}{l}\text { I intend to properly clean and } \\
\text { sanitize food contact surfaces }\end{array}$ & 1 & 2 & 3 & 4 & 5 & 6 & 7 \\
\hline
\end{tabular}

